\title{
SINGLE-BLIND, RANDOMIZED, CONTROLLED TRIAL OF PELVIC FLOOR MUSCLE TRAINING, ELECTRICAL STIMULATION, VAGINAL CONES, AND NO ACTIVE TREATMENT IN THE MANAGEMENT OF STRESS URINARY INCONTINENCE
}

\author{
Rodrigo A. Castro, Raquel M. Arruda, Miriam R. D. Zanetti, Patricia D. \\ Santos, Marair G. F. Sartori, Manoel J. B. C. Girão
}

doi: $10.1590 / \mathrm{S} 1807-59322008000400009$

Castro RA, Arruda RM, Zanetti MRD, Santos PD, Sartori MGF, Girão MJBC. Single-blind, randomized, controlled trial of pelvic floor muscle training, electrical stimulation, vaginal cones, and no active treatment in the management of stress urinary incontinence. Clinics. 2008;63:465-72.

PURPOSE: To compare the effectiveness of pelvic floor exercises, electrical stimulation, vaginal cones, and no active treatment in women with urodynamic stress urinary incontinence.

PATIENTS AND METHODS: One hundred eighteen subjects were randomly selected to recieve pelvic floor exercises (n=31), ES ( $n=30)$, vaginal cones $(n=27)$, or no treatment (untreated control) $(n=30)$. Women were evaluated before and after completion of six months of treatment by the pad test, quality of life questionnaire (I-QOL), urodynamic test, voiding diary, and subjective response.

RESULTS: In the objective evaluation, we observed a statistically significant reduction in the pad test ( $\mathrm{p}=0.003)$, in the number of stress urinary episodes $(\mathrm{p}<0.001)$, and a significant improvement in the quality of life $(\mathrm{p}<0.001)$ in subjects who used pelvic floor exercises, electrical stimulation, and vaginal cones compared to the control group. No significant difference was found between groups in the urodynamic parameters. In the subjective evaluation, $58 \%, 55 \%$, and $54 \%$ of women who had used pelvic floor exercises, electrical stimulation, and vaginal cones, respectively, reported being satisfied after treatment. In the control group, only $21 \%$ patients were satisfied with the treatment.

CONCLUSION: Based on this study, pelvic floor exercises, electrical stimulation, and vaginal cones are equally effective treatments and are far superior to no treatment in women with urodynamic stress urinary incontinence.

KEYWORDS: Stress urinary incontinence. Electrical stimulation. Pelvic floor exercise. Vaginal cones. Urodynamic.

\section{INTRODUCTION}

Urinary incontinence is generally defined as the involuntary loss of urine. It produces serious economic, social, and psychological problems that have a significant impact on women's health. ${ }^{1}$ Its prevalence ranges from $3 \%$ to $55 \%$ depending on the definition of incontinence used

Urogynecology and Vaginal Surgery Section of the Department of Gynecology, Universidade Federal de São Paulo - São Paulo/SP, Brazil. Email: rodrigo.castro@uol.com.br

Received for publication on March 26, 2008

Accepted for publication on May 05, 2008 and the age of the population studied. ${ }^{2}$ Urinary incontinence affects approximately 29.5 million Americans and costs an estimated 26.4 billion dollars annually in the United States (US). ${ }^{3,4}$

Stress urinary incontinence (SUI) is involuntary leakage of urine during effort, exertion, sneezing, or coughing. ${ }^{1}$ It is the most common type of urinary incontinence in women, and 1/3 of women present with symptoms of SUI in a pure or mixed form. ${ }^{3}$ In 1997 , this disease was treated with fewer than 130,000 antiincontinence procedures in the US. ${ }^{5}$

Several conservative treatment options are avaiable for the management of SUI, e.g., physical therapies, behavioral 
modification, and pharmacological intervention. ${ }^{3}$ Physical therapies involving pelvic floor muscle training with or without other treatments such as vaginal cones, biofeedback, and electrical stimulation are the standard for conservative treatment and prevention of SUI. ${ }^{6}$ However, few studies have directly compared the clinical efficacy and urodynamic outcomes of the different treatment options. ${ }^{6,7}$

According to a review by Cochrane, pelvic floor muscle training must be included in the first-line of conservative management programs for women with SUI, but randomized controlled trials evaluating the use of electrical stimulation and vaginal cones have provided inconclusive results. ${ }^{7}$ To assess if there is a difference between each of the modalities pelvic floor muscle training versus electrical stimulation versus vaginal cones, and to determine if one or more are effective than no active treatment, we conducted a randomized, single-blinded, controlled trial comparing these physical therapies in the management of women with stress urinary incontinence.

\section{PATIENTS AND METHOD}

Women with proven urodynamic stress urinary incontinence were successively enrolled in this singleblinded, controlled, randomized trial at the Urogynecology and Reconstructive Pelvic Surgery, a division of the Gynecology Department at the Federal University of São Paulo.

Subjects were required to have urodynamic stress incontinence and no detrusor overactivity, a positive cough stress test, and $>3 \mathrm{~g}$ leakage measured by a pad test with a standardized bladder volume $(200 \mathrm{ml}){ }^{8}$ All subjects had symptoms of SUI with an average of at least 3 stress incontinence episodes a week. Additional major exclusion factors included patients with chronic degenerative diseases that would affect muscular and nerve tissues, advanced genital prolapses, pregnancy, active or recurrent urinary tract infections, vulvovaginitis, atrophic vaginitis, continence surgery within one year, and patients with cardiac pacemakers. We also excluded patients with intrinsic sphincteric deficiencies identified by the Valsalva leak point pressure $\leq 60 \mathrm{~cm} \mathrm{H}_{2} 0$ measurement in the sitting position with a volume of $250 \mathrm{ml}$ in the bladder and/or by the measurement of a urethral closure pressure $\leq 20 \mathrm{~cm} \mathrm{H}_{2} 0$ in the sitting position at maximum cystometric capacity. The study was approved by the Institutional Review Board Committe from the Federal University of São Paulo. Each participant signed a written consent. The power calculation of the study was based on the power estimate and results of a previous study designed to detect differences between groups of $1 \mathrm{SD}$, with a 0.05 significance level and power of 0.8. In the previous study, significant differences in the same outcomes were shown in groups of 23 and 31 subjects; therefore, 30 participants were recruited for each of the four groups in this trial. ${ }^{9-14}$

Once enrolled by a physician investigator, subjects were assigned to four distinct groups: pelvic floor exercises, electrical stimulation, vaginal cones, or untreated controls. The division of the four groups was undertaken by using computer-generated random numbers prepared by the Biostatistics Center of the Federal University of São Paulo. The investigator responsible for assessing patients outcomes (RAC) was not involved in administering any of the treaments and was blind to the group assignments.

\section{Outcome mesures}

At the initial visit, all subjects underwent a complete medical history and physical examination including a pad test with a standardized bladder volume $(200 \mathrm{ml}),{ }^{8}$ a voiding diary recording the number of incontinence episodes during 7 days, and vaginal muscle strength assessment using the Oxford grading system. A urodynamic evaluation was also performed. Methods, definitions, and units conformed to standards proposed by the International Continence Society. ${ }^{1}$ All study subjects were also asked to complete the validated Incontinence Quality of Life Questionnaire (I-QoL) ${ }^{15}$ containing one section. A score of 100 represented the best possible quality life, and 0 represented the worst possible quality of life. ${ }^{15}$

The primary outcome measurement was the objective cure of stress incontinence based on a negative pad test with a standardized bladder volume ${ }^{8}(<2 \mathrm{~g}$ in weight). Secondary outcome measures included changes in the validated quality of life questionnaire (I-QoL), ${ }^{9}$ the number of leakages in the voiding diary, and the urodynamic test. A subjective curing of SUI was measured by a simple question as to how the patient felt about her incontinence problem after treatment. The only two answer options available were "satisfied" and "dissatisfied". Answering "satisfied" indicated that the patient did not want a different treatment. Answering "dissatisfied" indicated that the patient wanted a treatment different than the initial one.

\section{Interventions}

Qualified instructors provided subjects with explanations about the anatomy of the pelvic floor muscle and lower urinary tract, physiology, and continence mechanisms. All subjects were taught to contract the pelvic floor muscles correctly, and this was assessed by vaginal palpation. In the active group, the subjects were told that the three treatments 
were expected to be equally effective during a six-month trial period.

\section{Pelvic Floor Muscle Training group}

Once proper contractions were confirmed, the pelvic floor muscle training began. The sequence of contractions of the pelvic floor was as follows: 10 repetitions of 5 -second contractions with 5 seconds of recovery time; 20 repetitions of 2 -second contractions with 2 seconds of recovery; 20 repetitions of 1 -second contractions with 1 second of recovery; 5 repetitions of 10 -second contractions with 10 seconds of recovery followed by 5 repetitions of strong contractions together with stimulated cough with a 1-minute interval between sets. All the sessions were held in groups for 45 minutes. At the beginning of each session, general warm-up exercises of the joints were performed, and stretching exercises of the hips, adductors, hamstrings, and paravertebral muscles were performed at the end of the session.

\section{Electrical stimulation group}

The electrodes used for the transvaginal electrical stimulation (ES) were cylindrical and approximately 10 $\mathrm{cm}$ long and $3.5 \mathrm{~cm}$ wide, with a double metal ring. The electrodes were inserted into the middle third of the vagina, close to the sciatic spine and next to the pudendal nerve, at the level of the pubococcygeal muscle. The electrical parameters selected were a $50 \mathrm{~Hz}$ frequency, 5 -second-on and 10 -second-off cycle, and a pulse width of 0.5 milliseconds. The bipolar square wave could be delivered over a range that varied from 0 to $100 \mathrm{~mA}$, depending on the maximum current intensity comfortably tolerated by the patient. Each treatment was given for 20 minutes.

\section{Vaginal cones group}

Subjects treated with the weighted vaginal cones received nine cones of equal shape and volume, increasing in weight from 20 to $100 \mathrm{~g}$. Starting with the lightest weight, women were taught to place the cone into the vagina while standing. The heaviest weight that could be retained in place for one minute without voluntarily contracting the pelvic floor was called the passive cone. The patient would then use the next heavier weight that required a voluntary contraction of the pelvic floor to prevent the cone from slipping out of the vagina. The heaviest weight that could be retained with muscular contraction was the active cone. Women were instructed to do the exercises with cones for 45 minutes.

For all three intervention groups, sessions were performed at our urogynecology unit three times a week with the supervision of a trained physical therapist. The subjects in the untreated control group had no contact with the therapist during the trial, but they received a motivational phone call once a month during the intervention period.

Adverse events and compliance with all treatments were recorded in a training diary updated by the physical therapist in charge of the sessions during each clinic visit.

\section{Statistical analysis}

We analyzed the data only for those women who completed the study. Data were entered using Excel software and analyzed by SAS 8.1 (SAS Institute, Cary, North Carolina). $\mathrm{P}<0.05$ was considered statistically significant. The data are presented as mean $\pm \mathrm{SD}$, with the range in parentheses, or frequency. For the continuous variables of interest, the Kruscal-Wallis test was used to compare the differences among the four groups and was followed by the Mann-Whitney U test if the overall difference was statistically significant. In the MannWhitney $\mathrm{U}$ test, the significance level was adjusted to 0.008 by the number of comparisons. The chi-square test was used to examine the differences in categorical characteristics among groups.

\section{RESULTS}

A total of 118 women were randomized into four groups, $17(14 \%)$ of whom withdrew from the study, leaving a total of 101 subjects who completed the trial. Nine $(7.6 \%)$ of the women abandoned the study for lack of clinical improvement less than six weeks of treatment: two belonged to the pelvic floor muscle training group, one from the electrical stimulation group, four from the vaginal cone group, and two from the untreated group. Eight $(6.4 \%)$ of the women withdrew their consent and could not complete the study (change of city, family problems, pregnancy): one from the pelvic floor muscle training group (pregnancy), two from the electrical stimulation group (family problem, pregnancy), two from the vaginal cone group (family problems, change of city), and three women from the untreated group (change of city) (Figure 1). This left 26 women in the pelvic floor muscle training, 27 in the electrical stimulation group, 24 in the vaginal cones group, and 24 in the untreated group (Figure 1).

At baseline, there were no significant differences between the groups in any of demographics, clinical characteristics, or outcome measurements such as age, BMI, pregnancy, parity, hormonal status, duration of symptoms, vaginal 


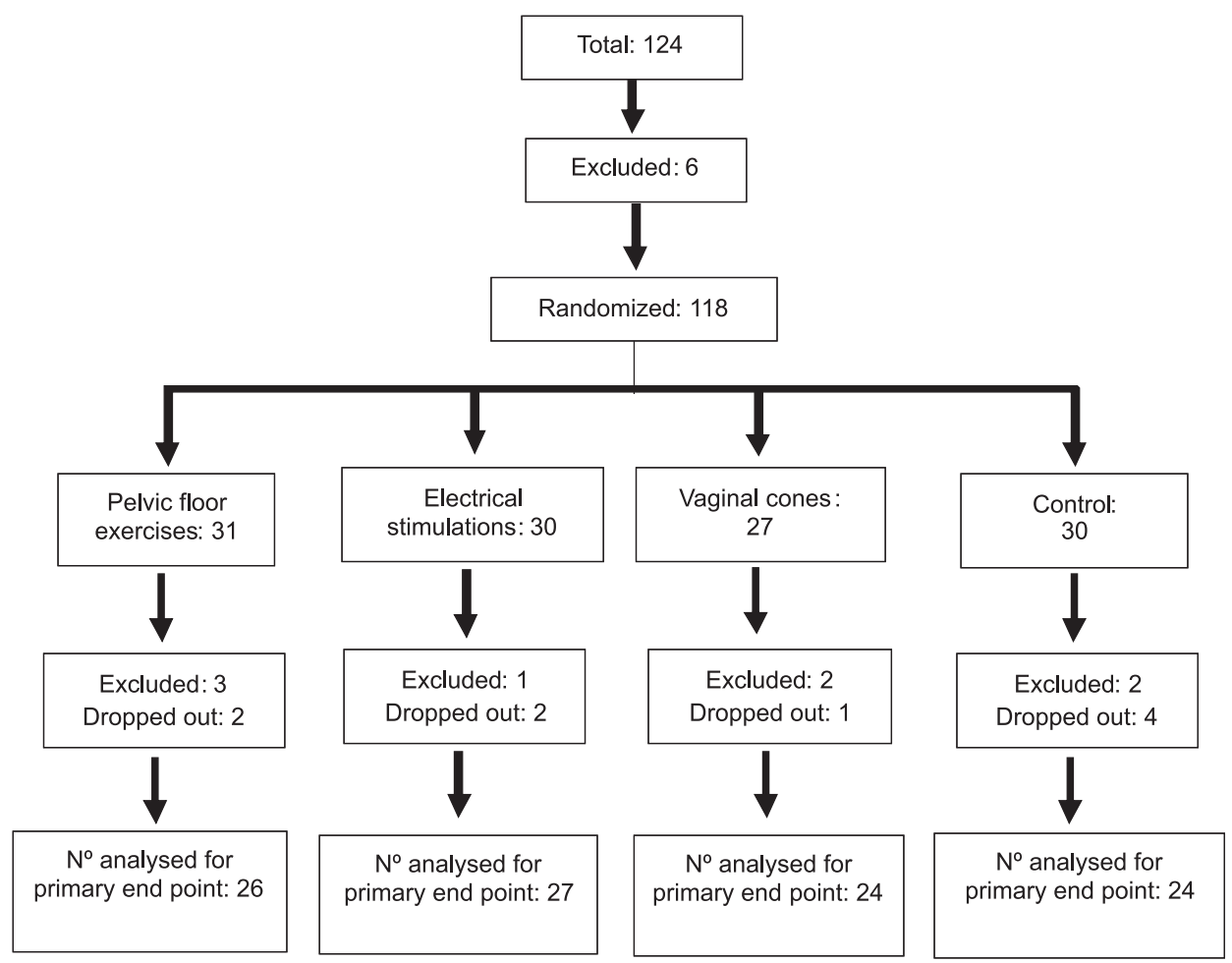

Figure 1- Flow of participants through trial

deliveries, number of C-sections, hysterectomy, previous surgery for stress urinary incontinence, pad test, I-QOL questionaire, voiding diary, muscle strength, and urodynamic parameters. The race variable proved statistically different among the groups analyzed; i.e., groups that carried out eletrical stimulation and vaginal cones were composed of predominantly white women compared to the pelvic floor muscle training and untreated groups (Tables 1,2,3).

Subject compliance was acceptable, with a mean compliance of $92 \%$ in the pelvic floor muscle training group, $91 \%$ in the electrical stimulation group, and $93 \%$ in the vaginal cones group after six months of treatment.

Table 1 - Baseline demographic and clinical characteristics by treatment group

\begin{tabular}{|c|c|c|c|c|c|c|}
\hline Variables & & $\begin{array}{l}\text { PFMT } \\
n=26\end{array}$ & $\begin{array}{l}\mathrm{ES} \\
\mathrm{n}=27\end{array}$ & $\begin{array}{l}\text { Cones } \\
\mathrm{n}=24\end{array}$ & $\begin{array}{l}\text { Control } \\
n=24\end{array}$ & $P$ value* \\
\hline \multirow[t]{2}{*}{ Race } & White & $12(57.1)$ & $14(60.9)$ & $20(95.2)$ & $18(75.0)$ & 0.024 \\
\hline & Non-White & $9(42.9)$ & $9(39.1)$ & $1(4.8)$ & $6(25.0)$ & \\
\hline Age & & $56.2 \pm 12.5$ & $55.2 \pm 12.8$ & $52.6 \pm 11.2$ & $52.6 \pm 11.2$ & 0.788 \\
\hline BMI & & $25.9 \pm 5.0$ & $21.9 \pm 3.9$ & $24.1 \pm 4.6$ & $26.9 \pm 5.1$ & 0.180 \\
\hline Durations of Symptoms & & $4.9 \pm 3.0$ & $5.0 \pm 3.9$ & $3.2 \pm 2.1$ & $6.0 \pm 4.9$ & 0.236 \\
\hline Pregnancy & & $3.9 \pm 2.3$ & $5.1 \pm 3.2$ & $4.2 \pm 2.5$ & $4.8 \pm 3.0$ & 0.644 \\
\hline Vaginal delivery & & $2.8 \pm 1.9$ & $3.5 \pm 2.6$ & $3.0 \pm 2.1$ & $3.1 \pm 2.7$ & 0.896 \\
\hline C-section delivery & & $0.5 \pm 0.9$ & $0.7 \pm 0.9$ & $0.6 \pm 0.8$ & $0.8 \pm 1.0$ & 0.489 \\
\hline No (\%) menopausal & & $11(47.8)$ & $11(45.8)$ & $10(47.6)$ & $9(42.9)$ & 0.987 \\
\hline No $(\%)$ hormone replacement therapy & & $3(33)$ & $3(27)$ & $3(30)$ & $3(27)$ & 0.925 \\
\hline No (\%)hysterectomy & & $3(13)$ & $4(16)$ & $3(14)$ & $3(14)$ & 0.890 \\
\hline No (\%) Previous incontinence surgery & & $4(17)$ & $7(29)$ & $4(20)$ & $4(19)$ & 0.762 \\
\hline
\end{tabular}

$\ddagger$ Data presented as mean $\pm \mathrm{SD}$, data in parenthesis are percentages; * Denotes overall comparison among four groups using Kruskal -Wallis test or chisquare test 


\section{Primary outcome measurement}

A negative pad test with a standardized bladder volume was observed in $12(46 \%)$ subjects in the pelvic floor PFMT group, $13(48 \%)$ in the ES group, $11(46 \%)$ in the vaginal cone group, and only $2(8.0 \%)$ in the untreated control group, respectively. There was a significant decrease in the pad weight in all groups, but, when the analysis was carried out among the groups, we noted that patients who used active treatment showed a significant decrease in pad weight when compared to the control group $(\mathrm{p}=0.003)$ (Table 2). There was no significant difference of these measurements between the three physical therapy techniques after six months of treatment (Table 3).

\section{Secondary outcome measurements}

Results of the I-QoL Questionnaire are shown in Table 2. After six months, the active subject group showed a significant change in the quality of life compared to untreated controls $(p=0.002)$. The quality of life increased significantly in $28.4 \%$ of the PFMT group, $32.4 \%$ of the ES group, and $30.3 \%$ of the vaginal cones group. There was no modification in the untreated group $(-3.6 \%)$ (Table 2$)$. When we compared the active groups, no significant difference was identified between them (Table 3).

Analyzing the voiding diariy, the phisical therapy techniques had a significantly greater impact in decreasing the stress incontinence episodes compared with the control group $(\mathrm{p}<0.001)$ (Table 2$)$. There was no significant difference between the treatment groups (Table 3 ).

Changes in urodynamic parameters are summarized in Table 4. Stress testing for urodynamic stress incontinence was negative at the cystometry in $10(38 \%), 11(41 \%), 9$ $(37 \%)$, and $3(12 \%)$ of the subjects in the PFMT, ES, vaginal cones, and untreated control groups, respectively. Initial bladder capacities and maximum sensation and residual urine were normal in all subjects and did not change significantly after treatment. Average and maximum flow rates in fluxometry were within a normal range in all subjects before and after treatment. Maximun urethral closure pressure or functional profile length on urethral pressure profile did not

Table 2 - Outcome measure and muscle strengh at baseline and 6 months divided by treatment group

\begin{tabular}{|c|c|c|c|c|c|}
\hline Variables & $\begin{array}{l}\text { PFMT } \\
n=26\end{array}$ & $\begin{array}{l}\mathrm{ES} \\
\mathrm{n}=27\end{array}$ & $\begin{array}{l}\text { Cones } \\
n=24\end{array}$ & $\begin{array}{l}\text { Control } \\
n=24\end{array}$ & $P$ value* \\
\hline IQoL questionaire $(\%)$ ( baseline) & $56.4(19.0)$ & $55.5(17.8)$ & $55.5(22.3)$ & $61.1(22.8)$ & 0.282 \\
\hline IQoL questionaire(\%) (6 months) & $82.2(17.6)$ & $83.4(12.1)$ & $82.7(14.2)$ & $57.6(28.2)$ & $0.002 * *$ \\
\hline IQoL questionaire(\%) (6 months-baseline) & $25.7(15.4)$ & $27.8(19.9)$ & $27.2(23.2)$ & $-3.6(14.0)$ & $<0.001 * *$ \\
\hline PAD Test volume (200 ml) (baseline) & $39.7(25.4)$ & $37.0(28.0)$ & $36.6(20.4)$ & $37.9(24.1)$ & 0.326 \\
\hline PAD Test volume (200 ml) (6 months) & $8.4(15.8)$ & $9.1(14.6)$ & $8.0(12.6)$ & $21.0(18.5)$ & $0.003 * *$ \\
\hline No $(\%)$ with weight $<2 \mathrm{~g}$ (6 month) & $12(46)$ & $13(48)$ & $11(46)$ & $3(8)$ & \\
\hline Voiding dairy 7days / leakages (baseline) & $10.3(10.1)$ & $12.7(12.0)$ & $12.6(4.4)$ & $10.5(7.0)$ & 0.710 \\
\hline Voiding dairy 7days / leakages (6 months) & $2.7(3.6)$ & $2.3^{\prime}(5.5)$ & $1.5(1.8)$ & $8.8(6.3)$ & $<0.001 * *$ \\
\hline Muscle strengh oxford scale (baseline) & $2.1(0.8)$ & $2.0(0.8)$ & $2.0(0.6)$ & $2.1(0.8)$ & 0.918 \\
\hline Muscle strengh oxford scale (6 months) & $3.6(0.71)$ & $2.9(1.00)$ & $3.0(0.89)$ & $2.3(1.07)$ & $0.002 * * *$ \\
\hline Subjective response Satisfied $\operatorname{No}(\%)$ (6 months) & $15(58)$ & $15(55)$ & $13(54)$ & $5(21)$ & \\
\hline Subjective response Dissatisfied No(\%) (6 months) & $11(42)$ & $12(45)$ & 11(46) & $19(79)$ & \\
\hline
\end{tabular}

* Data presented as mean(SD); * Denotes overall comparison among four groups using Kruskal -Wallis test or pairwise test using the Mann-Whittney U test; $* * 6$ months PFMT $=\mathrm{ES}=\mathrm{Cones} \neq \mathrm{Control} ; * * * 6$ months $\mathrm{PFMT} \neq \mathrm{ES}=\mathrm{Cones}=\mathrm{Control}$

Table 3 - Outcome measure and multiple comparison of all groups at 6 months

\begin{tabular}{|c|c|c|c|c|c|c|}
\hline Variaables & PFMT $v$ Control & ES $v$ Control & Cones $v$ Control & PFMT $v E S$ & PFMT $v$ Cones & ES $v$ Cones \\
\hline IQoL questionaire(\%) & $<0.001 *$ & $<0.001 *$ & $<0.001 *$ & 0.777 & 0.653 & 0.343 \\
\hline PAD Test volume (200 ml) & $0.001^{*}$ & $0.001^{*}$ & $0.002 *$ & 0.312 & 0.432 & 0.143 \\
\hline Voiding dairy 7days / leakages & $<0.001 *$ & $<0.001 *$ & $<0.001 *$ & 0.657 & 0.786 & 0.065 \\
\hline Muscle strengh oxford scale & $0.001 *$ & 0.06 & 0.07 & $0.002 *$ & $0.001 *$ & 0.121 \\
\hline
\end{tabular}

Mann-Whittney U tes; *Significant difference, $\mathrm{p}<0.008$ 
Table 4 - Urodynamic data at baseline and 6 months after treatment

\begin{tabular}{|c|c|c|c|c|c|}
\hline Cystometry & $\begin{array}{l}\text { PFMT } \\
n=26\end{array}$ & $\begin{array}{l}\text { ES } \\
n=27\end{array}$ & $\begin{array}{l}\text { Cones } \\
\mathrm{n}=24\end{array}$ & $\begin{array}{l}\text { Control } \\
\mathrm{n}=24\end{array}$ & $P$ value* \\
\hline Volume at first desire to void (ml) baseline & $133.7 \pm 51.4$ & $138.9 \pm 61.4$ & $129.3 \pm 50.6$ & $135.5 \pm 61.2$ & 0.929 \\
\hline Volume at first desire to void (ml) 6 months & $141.3 \pm 46.6$ & $147.9 \pm 75.9$ & $139.3 \pm 53.2$ & $136.2 \pm 47.7$ & 0.09 \\
\hline Maximun cystometric capacity (ml) baseline & $515.4 \pm 131.9$ & $531.1 \pm 157.4$ & $533.8 \pm 157.8$ & $520.9 \pm 154.1$ & 0.823 \\
\hline Maximun cystometric capacity $(\mathrm{ml}) 6$ months & $545.4 \pm 123.8$ & $579.3 \pm 142.6$ & $535.7 \pm 109.8$ & $473.8 \pm 107.9$ & 0.236 \\
\hline Post micturation residual $(\mathrm{ml})$ baseline & $1.4 \pm 3.5$ & $7.9 \pm 20.4$ & $4.6 \pm 10.0$ & $2.6 \pm 10.9$ & 0.880 \\
\hline Post micturation residual (ml) 6 months & $1.7 \pm 3.6$ & $7.5 \pm 15.0$ & $2.2 \pm 3.7$ & $7.8 \pm 17.1$ & 0.707 \\
\hline No (\%) with negative stress test (urodynamic) 6 months & $10(38)$ & $11(41)$ & $9(37)$ & $3(12)$ & \\
\hline \multicolumn{6}{|l|}{ Urethral pressure profile } \\
\hline Functional urethral lengh $(\mathrm{cm})$ baseline & $2.5 \pm 0.8$ & $3.1 \pm 3.9$ & $2.7 \pm 0.8$ & $2.4 \pm 0.9$ & 0.528 \\
\hline Functional urethral lengh $(\mathrm{cm}) 6$ months & $2.6 \pm 0.8$ & $2.5 \pm 0.7$ & $2.6 \pm 0.7$ & $2.3 \pm 0.7$ & 0.460 \\
\hline Maximum urethral closure pressure $(\mathrm{cm})$ baseline & $53.5 \pm 16.5$ & $52.2 \pm 18.9$ & $58.4 \pm 19.8$ & $61.2 \pm 28.1$ & 0.519 \\
\hline Maximum urethral closure pressure $(\mathrm{cm}) 6$ months & $53.4 \pm 13.0$ & $51.9 \pm 16.8$ & $56.9 \pm 16.0$ & $53.8 \pm 14.9$ & 0.518 \\
\hline \multicolumn{6}{|l|}{ Fluxometry } \\
\hline Maximum flow rate $\mathrm{ml} / \mathrm{s}$ baseline & $25.8 \pm 9.2$ & $30.4 \pm 9.7$ & $29.2 \pm 10.8$ & $25.8 \pm 8.3$ & 0.614 \\
\hline Maximum flow rate $\mathrm{ml} / \mathrm{s} 6$ months & $26.5 \pm 8.1$ & $29.3 \pm 11.3$ & $24.5 \pm 10.9$ & $27.4 \pm 8.1$ & 0.125 \\
\hline Avarage flow rate $\mathrm{ml} / \mathrm{s}$ baseline & $14.3 \pm 6.9$ & $14.1 \pm 6.4$ & $17.5 \pm 9.3$ & $15.4 \pm 7.5$ & 0.909 \\
\hline Avarage flow rate $\mathrm{ml} / \mathrm{s} 6$ months & $15.1 \pm 5.6$ & $16.9 \pm 7.1$ & $15.9 \pm 4.7$ & $16.7 \pm 5.8$ & 0.445 \\
\hline
\end{tabular}

$\ddagger$ Data presented as mean $\pm \mathrm{SD}$, data in parenthesis are percentages; * Denotes overall comparison among four groups using Kruskal -Wallis test

change after treatment in either treatment group.

Subjectively, 15 (58\%), 15 (55\%), 13 (54\%), and 5 (21\%) of the women in the pelvic floor muscle training, electrical stimulation, vaginal cone, and untreated control groups, respectively, claimed to be satisfied and did not desire a different treatment after the six month study treatment period (Table 2).

\section{Muscle strength}

There was no significant improvement in the muscle strength as measured by the Oxford scale in the untreated control group, but significant improvement was seen after six months of treament in the active groups. The improvement in the strength of the pelvic floor muscle was significantly greater in the PFMT group compared with the electrical stimulation and the vaginal cones groups $(\mathrm{p}=0.002)$ (Table 2). There was no significant difference in the muscle strength between electrical stimulation, vaginal cones, and untreated control groups (Table 3).

\section{DISCUSSION}

Urinary incontinence is a common health problen among women and is associated with a poor self-rated health, impairment in quality of life, social isolation, and symptoms of depression ${ }^{1}$ It has a complex pathophysiology, which calls for diferent therapeutic techniques depending on the mechanism involved in the origin of urine loss. ${ }^{16,17}$

The concept that neurologic and muscular injury of the pelvic floor causes genital prolapse and stress urinary incontinence has been proposed by several researchers. ${ }^{18-20}$ Because the pudendal nerve is an efferent nerve for both the pelvic floor muscle and the external urethral sphincter, its damage can generate both weakness of the pelvic floor, resulting in pelvic organ prolapsed, and relaxation of the external urethral sphincter, resulting in stress urinary incontinence. ${ }^{21}$ Thus, neuromuscular damage plays a fundamental role in maintaining continence and integrity of the pelvic floor.

Based on neuromuscular lesions, several treatments have arisen with the objective of reestablishing the function of muscles and nerves that make up the pelvic floor. Physical therapy techniques are capable of treating this disease, improving the muscle and nerve components of the pelvic organ support system. ${ }^{17}$

The treatment of stress urinary incontinence by pelvic floor muscle training, vaginal cones, and pelvic floor electrostimulation presents conflicting results. The difficulty in interpreting the literature may be seen in the meta-analysis carried out by Hay-Smith et al. (2007), who, despite having selected 43 randomized clinical studies, 
concluded that larger clinical trials with more concise methods were still needed. Statistical heterogeneity reflecting variations in incontinence type, training, and different outcome measurements are the problems that have made interpretation most difficult.

The high cost of this disorder, presently around 26 billion dollars in the US, as well as its high prevalence, ${ }^{2-4}$ raises this disease to the position of one of the most serious public health problems in the world, particularly in developing countries such as Brazil.

We analyzed and compared the effectiveness of pelvic floor muscle training, electrical stimulation, vaginal cones, and untreated control. Evaluating our results, we concluded that pelvic floor muscle training, electrical stimulation, and vaginal cones are effective in treating women with stress urinary incontinence. We observed a significant improvement in all outcome measures. The subjective rate of success of those physical therapies was approximately $56 \%$, and the objective (pad test) rate was approximately $47 \%$. Treatment was very well tolerated, and no adverse events, such as vaginal bleeding, urinary infection, and vulvovaginitis, could be correlated with any of the active treatments.

The most appropriate outcome measure for lower urinary tract symptoms is still undetermined. In a subjective analysis, Lagro-Janssen et al. (1991) observed a rate of $85 \%$ of cure and improvement after pelvic floor muscle training, although the authors point out that only $21 \%$ of the patients felt completely dry after treatment. The difficulty in analyzing this study lies in determining the true clinical behavior of the patients who improved after using pelvic floor exercises.

We attempted to use both objective and subjective outcome parameters in this study. A pad test with a standardized bladder volume was chosen as the primary outcome measure because it has been used in most clinical trials. In the the subjective analysis, we tried to reach what we understand is the "cure" to this condition..$^{22}$ The satisfaction of our patients meant that no other treatment, including a surgical procedure, was required. The nine women who abandoned the study for lack of clinical improvement underwent a tension-free vaginal tape procedure.

The significant improvements in quality of life that were demonstrated in this trial are important because they help us to understand the clinical relevance in the alterations in the pad test and voiding diary. The significant reduction in the number of stress urinary episodes and pad weight is responsible for more than a $30 \%$ increase in the quality of life in subjects who were treated using pelvic floor exercises, electrical stimulation, and vaginal cones.

The improvement in the strength of pelvic floor muscles was significantly greater in the PFMT group compared with electrical stimulation and vaginal cones. Our study has insufficient statistical power to observe any differences in the muscle strength between electrical stimulation treatment, vaginal cone treatment, and untreated controls (Table 3).

We did not observe any significant changes in regards to the urodynamic evaluation for most of the variables studied, including maximun urethral closure pressure, which could justify treatment success. However, it is important to remember that the correlation between clinical improvement and urodynamic changes remains controversial.

This study did not reproduce the data generated by Bo et al. (1999), in which pelvic floor muscle training was more effective than electrical stimulation, vaginal cones, and no treatment control for women with stress urinary incontinence. This discrepancy in results may be due to differences in how the two studies carried out active treatment. In the present study, a physiotherapist supervised all sessions, coordinated the pelvic floor exercises, increased the intensity of electrical impulses, and encouraged the use of vaginal cones. This engagement was probably responsible for the high compliance with active treatment and the favorable treatment outcomes based on subjective and objective measures, especially in the electrical stimulation and vaginal cone groups.

Despite the fact that all active groups were equally effective, pelvic floor muscle training must still be the first-line of conservative management programs for women with SUI. Electrical stimulation and vaginal cones should be offered to patients who cannot contract their pelvic floor muscle. Several studies have demonstrated that more than $30 \%$ of incontinent women are unable to contract their pelvic floor muscle correctly. ${ }^{23}$

We share the opinion that the therapeutic success of the physical therapy techniques depends on the degree of motivation of the woman. For this reason, we consider the association of an education program extremely important so that subjects can understand their disease and choose the best treatment.

In conclusion, this study provides evidence that pelvic floor muscle training, electrical stimulation, and vaginal cones are equally effective and better than no treament in the management of women with urodynamic stress urinary incontinence. Also, our study supports the idea that pelvic floor muscle exercise should be offered as the first choice of treatment. 


\section{REFERENCES}

1. Abrams P, Cardozo L, Fall M, Griffiths D, Rosier P, Ulmsten U, et al. The standardisation of terminology of lower urinary tract function: report from the Standardisation Sub-Committee of the International Continence Society. Neurourol Urodyn. 2002;21:167-78.

2. Holroyd-Leduc JM, Straus SE. Management of urinary incontinence in women: scientific review. JAMA. 2004;291:986-95.

3. Dmochowski RR, Miklos JR, Norton PA, Zinner NR, Yalcin I, Bump RC. Duloxetine Urinary Incontinence Study Group. Duloxetine versus placebo for the treatment of North American women with stress urinary. J Urol. 2004;170:1259-63.

4. Wagner TH, Hu TW. Economic costs of urinary incontinence in 1995. Urology Dysfunct. 1998;51:355-61.

5. Brown JS, Waetjen LE, Subak LL, Thom DH, Van den Eeden S, Vittinghoff E. Pelvic organ prolapse surgery in the United State, 1997. Am J Obstet Gynecol. 2002;186:712-16.

6. Berghmans LCM, Hendrikis HJM, Bo K, Hay-Smith EJ, de Bies RA, van Waalwijk, van Doorn ESC. Conservative treatment of stress urinary incontinence in women: a systematic review of randomized clinical trials. Br J Urol. 1998; 82:181-89.

7. Hay-Smith EJ, Bø Berghmans LC, Hendriks HJ, de Bie RA, van Waalwijk van Doorn ES. Pelvic floor muscle training for urinary incontinence in women. Cochrane Database Syst Rev. 2007;(1):CD001407.

8. Lose G, Rosenkilde P, Gammelgaard J, Schroeder. T. Pad-weighing test performed with standardized bladder volume. Urology. 1988;32:7880.

9. Olah KS, Bridges N, Denning J, Farrar DJ. The conservative management of patients with symptoms of stress incontinence: a randomized, prospective study comparing weighted vaginal cones and interferential therapy. Am J Obstet Gynecol. 1990;162:87-92.

10. Lagro-Janssen TL, Debruyne FM, Smits AJ, van Weel C. Controlled trial of pelvic floor exercises in the treatment of urinary stress incontinence in general practice. Br J Gen Pract. 1991;41:445-49.

11. Sand PK, Richardson DA, Staskin DR, Swift SE, Appell RA, Whitmore KE, et al. Pelvic floor electrical stimulation in the treatment of genuine stress incontinence: a multicenter, placebo-controlled trial. Am J Obstet Gynecol. 1995; 173:72-79.
12. Brubaker L, Benson JT, Bent A, Clark A, Shott S. Transvaginal electrical stimulation for female urinary incontinence. Am J Obstet Gynecol. 1997;177:536-40.

13. Bo K, Talseth T, Holme I. Single blind, randomise controlled trial of the pelvic floor exercises, electrical stimulation, vaginal cones and no treatment in management of genuine stress incontinence in women. $\mathrm{Br}$ Med J. 1999;318:487-93.

14. Wang AC, Wang YY, Chen MC. Comparison of electric stimulation and oxybutynin chloride in management of overactive bladder with special reference to urinary urgency: a randomized placebo-controlled trial. Urology. 2004;63:61-66.

15. Patrick DL, Martin ML, Bushnell DM, Yalcin I, Wagner TH, Buesching DP. Quality of life of women with urinary incontinence: further development of the incontinence quality of life instrument (I-QOL). Urology. 1999;53:1072.

16. DeLancey JOL. Stress urinary incontinence: where are we now, where should we go? Am J Obste Gynecol. 1996;175:311-19.

17. Handa VL, Harris TA, Ostergard DR. Protecting the pelvic floor: obstetric management to prevent incontinence and pelvic organ prolapse. Obstet Gynecol. 1996;88:470-78.

18. Gilpin SA, Gosling JA, Smith ARB, Warrell DW. The pathogenesis of genitourinary prolapse and stress incontinence of urine: a histological and histhochemical study. Br J Obstet Gynaecol. 1989;96:15-23.

19. Smith ARB, Hosker GL, Warree DW. The role of pudendal nerve damage in the aetiology of genuine stress incontinence in women. Br J Obstet. Gynaecol 1989b 96:29-32.

20. Morley R, Cumming J, Weller R. Morphology and neuropathology of the pelvic floor in patient with stress incontinence.Int Urogynecol J. 1996; 7:3-12.

21. Chai TC, Steers WD. Neurphysiology of micturition and continence in women. Int Urogynecol Urol. 1997;8:85-97.

22. Freeman RM. What's a 'cure'? Patient-centred outcomes of treatments for stress urinary incontinence. Int Urogynecol J Pelvic Floor Dysfunct. 2007;18:13-18.

23. Bo K. Pelvic floor muscle strength and response to pelvic floor muscle training for stress urinary incontinence. Neurourol Urodyn. 2003;22:654-58. 